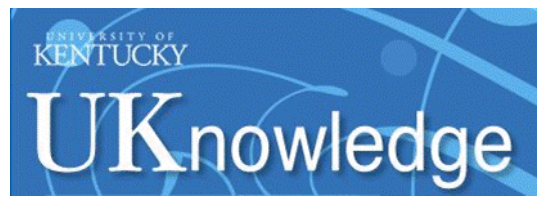

University of Kentucky

UKnowledge

\title{
Mice with Infectious Colitis Exhibit Linear Growth Failure and Subsequent Catch-Up Growth Related to Systemic Inflammation and IGF-1
}

Mark D. DeBoer

University of Virginia

Vidhya Vijayakumar

University of Virginia

Meiqing Gong

University of Virginia

John L. Fowlkes

University of Kentucky, fowlkesjohnl@uky.edu

Rachel M. Smith

University of Virginia

Follow this and additional works at: https://uknowledge.uky.edu/diabetes_facpub 3 next page for additional authors

Part of the Bacteria Commons, and the Nutrition Commons

Right click to open a feedback form in a new tab to let us know how this document benefits you.

\section{Repository Citation}

DeBoer, Mark D.; Vijayakumar, Vidhya; Gong, Meiqing; Fowlkes, John L.; Smith, Rachel M.; Ruiz-Perez, Fernando; and Nataro, James P., "Mice with Infectious Colitis Exhibit Linear Growth Failure and Subsequent Catch-Up Growth Related to Systemic Inflammation and IGF-1" (2017). Barnstable Brown Diabetes Center Faculty Publications. 7.

https://uknowledge.uky.edu/diabetes_facpub/7

This Article is brought to you for free and open access by the Diabetes at UKnowledge. It has been accepted for inclusion in Barnstable Brown Diabetes Center Faculty Publications by an authorized administrator of UKnowledge. For more information, please contact UKnowledge@lsv.uky.edu. 


\title{
Mice with Infectious Colitis Exhibit Linear Growth Failure and Subsequent Catch- Up Growth Related to Systemic Inflammation and IGF-1
}

\author{
Digital Object Identifier (DOI) \\ https://doi.org/10.1016/j.nutres.2017.02.005 \\ Notes/Citation Information \\ Published in Nutrition Research, v. 39, p. 34-42. \\ (C) 2017 Elsevier Inc. All rights reserved.
}

This manuscript version is made available under the CC-BY-NC-ND 4.0 license https://creativecommons.org/licenses/by-nc-nd/4.0/.

The document available for download is the author's post-peer-review final draft of the article.

\section{Authors}

Mark D. DeBoer, Vidhya Vijayakumar, Meiqing Gong, John L. Fowlkes, Rachel M. Smith, Fernando RuizPerez, and James P. Nataro 


\title{
Mice with infectious colitis exhibit linear growth failure and subsequent catch-up growth related to systemic inflammation and IGF-1
}

\author{
Mark D. DeBoer, MD, MSc., MCR ${ }^{1,3,5}$, Vidhya Vijayakumar, Ph.D ${ }^{2,3}$, Meiqing Gong, BSc. ${ }^{2,3}$, \\ John L. Fowlkes, MD ${ }^{4}$, Rachel M. Smith, MSc. ${ }^{2,3}$, Fernando Ruiz-Perez, Ph.D ${ }^{2,3}$, and James \\ P. Nataro, MD, Ph.D. 2,3 \\ ${ }^{1}$ Division of Pediatric Endocrinology, University of Virginia, Charlottesville, VA \\ ${ }^{2}$ Division of Pediatric Infectious Disease, University of Virginia, Charlottesville, VA \\ ${ }^{3}$ Department of Pediatrics, University of Virginia, Charlottesville, VA \\ ${ }^{4}$ Barnstable Brown Diabetes Center and Division of Pediatric Endocrinology, Department of \\ Pediatrics, University of Kentucky, Lexington, KY
}

\begin{abstract}
In developing communities, intestinal infection is associated with poor weight gain and lineargrowth failure. Prior translational animal models have focused on weight gain investigations into key contributors to linear growth failure have been lacking. We hypothesized that murine intestinal infection with Citrobacter-rodentium would induce linear-growth failure associated with systemic inflammation and suppressed serum levels of insulin-like growth factor-1 (IGF-1). We evaluated 4 groups of mice infected or sham-infected on day-of-life 28: uninfected-controls, wild-type $C$.rodentium-infected, partially-attenuated $C$. rodentium-infected (with deletion of 3 serine protease genes involved in colonization), and pair-fed (given the amount of daily food consumed by the wild-type $C$.-rodentium group). Relative to the uninfected group, mice infected with wild-type $C$. rodentium exhibited temporal associations of lower food intake, weight loss, linear-growth failure, higher IL-6 and TNF-a and lower IGF-1. However, relative to the pair-fed group, the $C$.rodentium-infected group only differed significantly by linear growth and systemic inflammatory cytokines. Between post-infection days 15-20, the infected group exhibited resolution of systemic inflammation. Between days 16-20, both wild-type $C$.-rodentium and pair-fed groups exhibited rapid linear-growth velocities exceeding the uninfected and mutant $C$-rodentium groups; during this time levels of IGF-1 increased to match the uninfected group. We submit this as a model providing important opportunities to study mechanisms of catch-up growth related to intestinal inflammation. We conclude that in addition to known effects of weight loss, infection with $C$.
\end{abstract}

\footnotetext{
${ }^{5}$ Author to whom correspondence should be addressed: P.O. Box 800386, University of Virginia, Charlottesville, VA 22908, Phone: 434-924-5956, Fax: 434-924-9181, deboer@ virginia.edu.

Publisher's Disclaimer: This is a PDF file of an unedited manuscript that has been accepted for publication. As a service to our customers we are providing this early version of the manuscript. The manuscript will undergo copyediting, typesetting, and review of the resulting proof before it is published in its final citable form. Please note that during the production process errors may be discovered which could affect the content, and all legal disclaimers that apply to the journal pertain.
} 
rodentium induces linear-growth failure potentially related to systemic inflammation and low levels of IGF-1, with catch-up of linear growth following resolution of inflammation.

\section{Keywords}

diarrhea; Citrobacter rodendium; growth failure; inflammation; insulin-like growth factor-1

\section{Introduction}

Infectious diarrhea continues to affect children worldwide, with an estimated mortality of over 700,000 children yearly [1]. While diarrhea-related mortality has decreased over the past 20 years, morbidity persists, including nutritional deficits, and retardation of linear and ponderal growth [2]. The underlying mechanisms of poor linear growth in these settings remain unclear including whether the weight and height deficits are related to decreased food intake, systemic inflammation, poor absorption of nutrients, and dysregulation of systemic growth factors such as insulin-like growth factor (IGF)-1 [3, 4]. Persistent length/ height measurement of more than two standard deviations below the mean (i.e., stunting) affects many of these children, even after resolution of the intestinal infections [5, 6]. Other children exhibit compensatory catch-up growth, an accelerated growth velocity that partially or completely normalizes their height $[7,8]$. To date, animal models have focused on weight loss, with few translational animal models to study these complex linear-growth-impacting phenomena [9].

One mouse model to study the sequelae of infectious diarrhea involves inoculation with Citrobacter rodentium [10]. While this bacterial strain is not a human pathogen, it features virulence factors similar to those of human diarrheagenic pathogens and mimics the effect of human infectious diarrhea, with prior studies demonstrating significant weight loss, though the effect on linear growth has not been assessed in detail [11]. The noted weight loss is potentially related to decreased food intake, poor absorption of nutrients or increased energy expenditure during infection $[10,11]$. However, the pathophysiology related to any linear growth deficits in this model remains unclear.

The goal of the current studies is to evaluate and explore temporal relationships between weight gain, growth failure, and changes in serum levels of IGF-1 and systemic cytokines over the course of infection with $C$. rodentium. We hypothesize that mice infected with $C$. rodentium (relative to sham-infected mice and relative to pair-fed controls who are only given as much daily food as the infected mice had consumed) will exhibit poor linear growth related to systemic inflammation and lower levels of IGF-1. We further hypothesize that following clearance of their infection, growth-stunted mice will exhibit "catch-up" growth, to obtain lengths and weights consistent with those of the uninfected group. The results of these studies provide for a novel and translationally relevant animal model to study mechanisms of catch up growth following intestinal infection. 


\section{Methods and materials}

\subsection{Animal care and infection}

All animal studies were carried out in strict compliance with the recommendations in the Guide for the Care and Use of Laboratory Animals of the National Institutes of Health. The protocol was approved by the University of Virginia Animal Care and Use Committee (protocol number 3894). All efforts were made to keep pain and suffering to a minimum. All animals were fed Teklad LM-485 laboratory chow 7012, which contains a proprietary formulation composed of ground corn, dehulled soybean meal, ground oats, wheat middlings, dehydrated alfalpha meal, soybean oil, corn gluten meal, and mineral and vitamin premixes (Envigo, Huntingdon, UK). The proximate analysis of the diet is shown in Table 1. The $C$. rodentium model was used as described previously [12, 13]. Briefly, over multiple sets of experiments, 3- to 4-week-old, C57BL/6 mice were purchased from Jackson Laboratories (Bar Harbor, ME). Mice were divided into 4 groups: those infected with wildtype $C$. rodentium, with a mutant strain of $C$. rodentium (with deletions of three serine protease autotransporters-encoding genes [ $c r c 1, c r c 2$ and adca] involved in colonization and pathogenesis $[12,14])$, an uninfected control group sham-treated with phosphate-buffered saline (PBS) at time of infection, and a group pair-fed the same food quantity as that consumed by the wild-type $C$. rodentium mice. We included the mutant strain of $C$. rodentium because this strain had been demonstrated to induce less severe colitis compared to that seen following inoculation with wild-type C. rodentium (unpublished observations). This permitted analysis of whether any growth-related sequelae persisted even in the absence of fulminant disease.

On day of life 28 or 29 , mice from the infected groups were inoculated with approximately $10^{10}$ colony-forming units (CFU) of wild type $C$. rodentium ICC-180 or with the isogenic mutant strain described above. The bacterial inoculum was suspended in $200 \mathrm{uL}$ of PBS and administered by oral gavage using a 20 -gauge intubation needle. Control animals received $200 \mathrm{uL}$ of sterile PBS. Efficacy of infection was assessed by culture; fecal pellets were collected aseptically from each infected mouse, weighed, and emulsified in PBS. The number of viable $\mathrm{CFU}$ of $C$. rodentium bacteria per gram of feces was determined by plating serial dilutions of the samples on medium containing appropriate selective antibiotics [12]. Similarly, separate groups of mice were euthanized by anesthesia and cervical dislocation and had their colons removed for analysis of colonization. For enumeration of bacteria in the distal colon, a 2- to 3-cm section of the distal colon was excised. Lumenal contents were expelled and the colon segment was opened and rinsed thoroughly in PBS to remove fecal material, homogenized in $1 \mathrm{ml}$ PBS with a Handi-Shear tissue homogenizer (VirTis, Gardiner, NY), and diluted in PBS for plating on MacConkey agar. Finally, for assessment of stool quality over time, at specified time points after inoculation, fecal pellets were evaluated for stool consistency (categorized as solid, solid/soft, soft, watery) and for the presence of mucus or blood. At the experiment's end (following blood draw, if applicable), animals were euthanized via cervical dislocation under anesthesia. 


\subsection{Anthropometry measurements}

Weight was measured every-other-day using a digital scale (Tanita Corp., Arlingtron Heights, IL). Length measurements were performed every 4 days under sedation with isoflurane using a vaporizer (LEI Medical, Portland, OR) and digital calipers (Fisher Scientific, Waltham, MA)[15]. All measurements were performed twice; a third measurement was performed if these measures were greater than 5\% different from each other; the average of these measurements was then used. All length measurements were performed by a single investigator (MDD). Nose-anus measurements were made with the animal supine with gentle pressure to extend the neck, measuring from the furthest point on the animal's nose to the furthest point on the anus. Length measurements were performed with the investigator blinded to the treatment group for the first group of mice $(\mathrm{N}=10$ at baseline for each group). Blinding was not possible for subsequent sets of animals ( $\mathrm{N}=10$ for each group). However, measurements were compared between experiments and were not significantly different between sets within each group; therefore, data were combined for anthropometry measurements for each set of experiments.

\subsection{Pair-feeding}

Mice were stored in wire-rack cages with chow placed on the wire rack. Food intake was followed daily by weighing the food on the wire rack plus any portion that had fallen through, and subtracting from the previous day's food weight. For all groups except the pairfed group, this daily amount of food consumed was divided by the number of animals in the cage (up to 5 animals). Pair-fed animals were individually-housed and each pair-fed mouse was given only enough food to match the previous day's average per-mouse consumption by wild-type $C$. rodentium-infected animals. For pair-fed animals, food that was unconsumed by an individual mouse at the end of the 24-hour period (an occurrence only noted on days 17-20 post-infection) was weighed and provided to that animal again, in addition to that day's food allotment. For calculating total food intake, this unconsumed food portion was subtracted from what had been provided to the animal the previous day.

\subsection{Serum measurements}

For assessment of cytokines and IGF-1, serum was drawn via cardiac puncture under anesthesia from separate cohorts of animals at time of euthanizing on days 3, 7 and 10 after infection. An additional cohort of animals had live blood draw via facial vein under anesthesia performed at 15 days after infection via ophthalmic artery puncture for each treatment group and then terminal blood draw at day 20. We measured levels of serum cytokines to assess pro-inflammatory (IL-6 and TNF-a), anti-inflammatory (IL-10) and adaptive-immune-modulatory (INF- $\gamma$ ) cytokine responses during infection with $C$. rodentium. Quantification of serum cytokines was performed by the University of Virginia Immunology core using Milliplex Mouse Cytokine/Chemokine Panel 1 Assay (MilliporeSigma, Billerica, MA). Assays were performed according to the manufacturer's specifications and analyzed with a Luminex MagPix platform (Luminex Corp., Austin, TX). Fluorescence intensity from duplicate samples was averaged and transformed into protein concentration using a calibration curve obtained from recombinant cytokine standards analyzed with Milliplex Analyst 5.1 software (MilliporeSigma, St. Louis, MO). Serum 
IGF-1 measurement was performed on mouse serum using ELISA (IDS, Tyne \& Wear, UK and Crystal Chem, Downers Grove, IL) according to the manufacturers' instructions.

\subsection{Statistical Analysis}

We assessed data for normality using Excel (Microsoft, Seattle, WA) and Prizm (Graphpad, San Diego, CA) and log-transformed data for statistical comparison when not normally distributed (e.g. for serum levels of cytokines). Data are reported as means and standard error of the mean (SEM). Our primary outcome of interest was difference in length between the mice infected with wild-type $C$. rodentium and the pair-fed group. This comparison was performed using t-tests in Prizm. All other comparisons between groups were performed using analysis of variance (ANOVA) in Prizm. Because of uncertain mortality among treated mice, we began with $\mathrm{n}=20$ per group for wild-type $C$. rodentium, mutant $C$. rodentium and pair-fed mice and $n=15$ for uninfected controls. While we lacked prior variance data to perform a priori power calculations for the study, given the observed variance in each group and the number of mice surviving the experiment, we had $80 \%$ power to detect a difference of as little as 0.75 -standard deviation (approximately $2 \%$ of body length) between the mice infected with wild-type and the pair-fed group. Statistical significance was considered for $\mathrm{p}<0.05$. Mice that died before the end of the experiment were included in calculation of mortality by treatment group but were excluded from calculation of daily weight, length and food intake by group. Statistical comparison of food consumption amounts between groups (as well as calculation of SEM) was not valid because all mice who were not in the pair-fed group had per-mouse quantities calculated for each cage (minimizing the true variation in food consumption on an individual mouse basis), while pair-fed animals were all fed identical amounts of the average food consumed by the wild-type $C$-rodentium mice on a daily basis.

\section{Results}

\subsection{Infection efficacy and mortality}

Figure 1 shows $C$. rodentium shedding in stool and colonization in colon of mice following inoculation with wild-type $C$. rodentium or mutant $C$. rodentium. Inoculation resulted in a high infection efficiency with both wild-type $C$. rodentium and mutant $C$. rodentium, with bacterial shedding that continued above $10^{8} \mathrm{CFA} / \mathrm{gr}$ feces, continuing until at least 14 days after infection. Colonization was higher in mice infected with mice inoculated with wildtype $C$. rodentium compared to mutant $C$. rodentium by day 10 after inoculation.

Table 2 shows stool consistency and the presence of mucus and/or blood for each of the treatment groups. Uninfected and pair-fed mice maintained solid stool throughout, while mice infected with wild-type $C$. rodentium all had affected stools (soft or watery) on days days 4 and 7 (both $p<0.01$ vs. uninfected), with all mice exhibiting blood or mucus in stool by day 7 . Mice infected with mutant $C$. rodentium had a lower degree of soft stools by day 4 (20\% soft) and day 7 (60\% solid/soft) and did not have blood or mucus.

Mortality was significant among mice with wild-type $C$. rodentium infection, with $8 \%$ by 10 days and $32 \%$ by 15 days. One mouse from the mutant $C$. rodentium group died within 12 
hours of inoculation, leaving a total mortality of $4 \%$ for this group. There was one pair-fed mouse (5\%) that died at day 11 of unknown cause. There was no mortality among uninfected mice.

\subsection{Weight gain, linear growth and food intake}

Figure 2 shows food intake, weight gain, and length measures by treatment group. Food intake was relatively stable among uninfected mice and those infected with mutant $C$. rodentium (Figure 2A). Mice infected with wild-type $C$. rodentium exhibited a decrease in food intake starting day 7 after infection, with a nadir 10 days after infection, followed by a gradual increase in food intake above that of the uninfected animals by day 14 after infection. By design, food consumed by the pair-fed group matched the amount of food consumed by the wild-type $C$. rodentium group but with a 1-day delay in receiving this quantity.

Regarding weight gain, uninfected mice exhibited steady weight gain through the experiments (Figure 2B). Mice infected with wild-type $C$. rodentium exhibited a steady decrease in weight starting 4 days after infection, with a nadir at 13 days. These levels differed from uninfected mice on days starting at day 5 after infection (ANOVA $p<0.05$ on day 5 and $\mathrm{p}<0.001$ thereafter). Mice that were pair-fed the same amount of food as those with wild-type $C$. rodentium had weights that were higher than the $C$. rodentium group until day $9(\mathrm{p}<0.05)$; at that point they began losing weight, experiencing a deeper (though not significantly lower) nadir and more rapid re-gain of weight than seen for the wild-type $C$. rodentium this group, with a higher weight on day $17(\mathrm{p}<0.05)$. Pair-fed mice had weights that were significantly different from uninfected mice on days 11-15 after infection $(\mathrm{p}<0.001)$ and were different from mice infected with mutant $C$. rodentium on days 11-15 after infection ( $\mathrm{p}<0.001$ for days $11-13$ and $\mathrm{p}<0.05$ on day 15$)$. Finally, mice infected with a mutant strain of $C$. rodentium exhibited weight gain intermediate between that of the uninfected ( $\mathrm{p}<0.05$ for days $5-17$ ) and wild-type $C$. rodentium strain ( $<<0.01$ day 11 , $\mathrm{p}<0.001$ days $13-17$, and $\mathrm{p}<0.05$ day 19), without frank weight loss but with slower weight gain. During the time from day 15 to 19, both the wild-type C. rodentium and pair-fed groups gained weight faster than the uninfected group $(\mathrm{p}<0.001)$ and mutant $C$. rodentium group $(\mathrm{p}<0.01)$.

Regarding linear growth, mice in the uninfected and mutant $C$. rodentium groups exhibited steady linear growth (Figure 2C). Length among mice infected with wild-type $C$. rodentium plateaued by day 4 after infection and nose-anus length remained lower than uninfected mice thereafter $(\mathrm{p}<0.01$ on days $12-16)$ and lower than pair-fed mice days $12-16$ after infection $(\mathrm{p}<0.05)$. Mice that were pair-fed the same amount of food as those with wild-type C. rodentium exhibited some slowing of linear growth after on day 4 but were not significantly different than the uninfected mice thereafter. Again, mice infected with a mutant strain of $C$. rodentium exhibited linear growth intermediate between that of the uninfected and wild-type $C$. rodentium strain that was different from wild-type $C$. rodentium at days 12 and $16(\mathrm{p}<0.01)$. Both the wild-type $C$. rodentium and the pair-fed mice appeared to exhibit particularly brisk "catch-up growth" between days 16-20, when interval growth 
for both the wild-type $C$. rodentium $(\mathrm{p}<0.001)$ and pair-fed $(\mathrm{p}<0.05)$ groups was greater than the uninfected and triple mutant groups.

\subsection{Cytokines}

Levels of systemic cytokines over the course of the experiment are displayed in Figure 3. Relative to the uninfected group, mice infected with wild-type $C$. rodentium exhibited an increase in levels of IL- 6 and TNF-a starting 3 days after infection (for both IL-6 and TNFa $\mathrm{p}<0.001$ on day 15 after infection compared to all other groups). Mice in the pair-fed group had levels similar to the uninfected group, while mice infected with mutant $C$. rodentium displayed intermediate levels.

\subsection{IGF-1 levels}

IGF-1 levels over the course of the experiment are shown in Figure 4. Mice in the uninfected group exhibited a gradual increase in IGF-1 levels over time. By contrast, mice infected with wild-type $C$. rodentium experienced a decrease in IGF-1 levels, with a nadir at day 10 (ANOVA compared to uninfected group $\mathrm{p}<0.001$ days $7-15$; lower than the pair-fed group at day $10, p<0.01$ ). Subsequently there was a rise in IGF-1 levels above those of the uninfected group. Mice in the pair-fed group exhibited a later nadir in IGF-1 levels to the point where these were significantly below those of the uninfected group on days 7 and 15 after infection ( $p<0.01$ and $p<0.001$, respectively), and also exhibited an dramatic increase by day 20. Again, mice infected with mutant $C$. rodentium had IGF-1 levels that were intermediate between wild-type $C$. rodentium and uninfected mice and were significantly different from wild-type $C$. rodentium at days $7-15(\mathrm{p}<0.001)$ and different from the pair-fed group on days $7(\mathrm{p}<0.05)$ and $15(\mathrm{p}<0.001)$.

\section{Discussion}

While weight loss during infection with $C$. rodentium has been previously characterized, we have expanded assessment of the model to reveal linear growth failure during infection, followed by subsequent "catch-up" growth that outpaces the growth of uninfected animals. In this sense, we accepted our research hypothesis that mice infected with $C$. rodentium would exhibit linear growth failure. While weight loss in this model have been investigated [10], this is the first in-depth look into potential contributors to linear growth failure. The linear growth characteristics are similar to what is frequently seen children in developing areas worldwide, who frequently experience intestinal infections and have related shortfalls in linear growth [5] and for whom predictors of catch-up growth have remained elusive [9]. This model may serve as a novel means of assessing mechanisms of linear growth suppression and subsequent acceleration during onset and clearance of intestinal infections. These data may thus have significance for testing optimal interventions to improve growth in the setting of recurrent infections.

In this model, we were particularly interested in the relationships between nutrition, inflammation and growth. Poor weight gain in this setting was most strongly associated with a sharp decrease in food intake among infected animals. Mice infected with wild-type $C$. rodentium responded to infection with a decrease in food consumption and had a similar 
drop in weight as mice that were pair-fed the same amount of food as was consumed by the infected group. This apparent decrease in appetite has been noted previously in models of $C$. rodentium infection [16], though in evaluating growth responses to infection between infected and pair-fed groups, other investigators have assessed weight gain alone and not linear growth $[17,18]$.

In the current set of experiments, linear growth did not appear to be as tightly associated with nutrition. For instance, animals in the infected group exhibited a more significant linear growth faltering than those in the pair-fed group. While these observations are novel in the setting of $C$. rodentium infection, prior models of intestinal inflammation, such as following administration of trinitrobenzene sulfonic acid (TNBS), have also reported a greater degree of linear growth deficits among treated animals compared to pair-fed animals [19]. Animals with TNBS colitis given gavage feeding to deliver the same amount of calories consumed by the control group showed increases in weight gain, yet linear growth remained partially suppressed [19]. This suggested influences beyond the delivery of calories alone. Growth deficits not explained by nutrition alone have been proposed to result predominantly from inflammation $[19,20,21,22,23,24]$ or from suppression of growth factors in the setting of inflammation $[25,26]$.

With respect to the suppression of growth factors in our model, we noted lower levels of IGF-1 among mice infected with wild-type $C$. rodentium relative to the uninfected group at multiple time points and relative to the pair-fed group at day 10. Suppressed levels of IGF-1 have been noted in both states of malnutrition [4, 27, 28] and systemic inflammation [26, 29, 30]. In both of these scenarios, the low levels of IGF-1 appeared to result from growth hormone resistance at the level of the liver [28, 29, 30, 31, 32].

The mechanism for IGF-1 suppression among wild-type $C$. rodentium-infected animals in our model may be related to both inflammation and low food intake, given that 1) IGF-1 levels were initially lower in infected compared to pair-fed animals, 2) by day 15, infected and pair-fed animals later had similar levels of IGF-1 and 3) by day 20, infected and pair-fed animals had similar recovery (in fact, above levels seen among uninfected animals). Thus, whereas IGF-1 did not appear to play a central role in growth suppression in the later stages of infection and recovery, the role of IGF-1 in the initial suppression of growth in this model requires further evaluation. Furthermore, assessment for resistance to IGF-1 in the tissue is also warranted in this setting [33, 34].

With respect to systemic inflammation, however, there was a clear separation among the treatment groups, with levels of IL- 6 that were elevated by day 3 after infection and remained elevated up to day 15 . Levels of cytokines did not normalize until day 20 after infection, and this normalization was associated with a rapid increase in linear growth. This increase in linear growth was not seen in the pair-fed group, who exhibited low levels of the systemic inflammatory cytokines IL-6 and TNF-a. In this way, it appeared that the linear growth suppression among $C$. rodentium-infected mice was most strongly associated with these elevations in systemic inflammation. Clearly, more definitive investigations are needed to identify whether this suppression relates to direct effects of inflammatory and/or other cytokines at the growth plate itself or through other mechanisms [34, 35]. 
Our data suggest that catchup growth relates to both increased appetite and increased physiologic anabolic response to caloric intake. If these phenomena prevail as well in children, it would suggest the importance of assuring additional calories in the wake of an inflammatory infection. One important consideration regarding growth suppression in developing areas of the world is whether the growth deficits in early childhood: 1) are permanent, resulting in short adult height 2) will result in a delayed cessation of growth, resulting in normal adult height or 3) will resolve during early childhood, resulting in catchup growth that normalizes (or partially normalizes) height. Catch-up growth is recognized as an important process for children who have experienced growth suppression in early childhood [9]. Catch-up growth has been described as "a height velocity above the statistical limits of normality for age or maturity during a defined period of time, following a transient period of growth inhibition; the effect of catch-up growth is to take the child towards his/her pre-retardation growth curve [8]." However, the predictors and mechanisms of catch-up growth remain poorly understood [9], and animal models are needed to assess whether catch-up growth is related to hormonal changes or to changes at the level of the growth plate, including a delay in senescence and increased proliferation of cells at the growth plate $[9,36]$. Further research is needed in disease states involving mixed processes of inflammation and nutrition deficits to determine if catch-up growth is more strongly related to resolution of one process over the other. We submit that the model of catch-up growth following infection with $C$. rodentium represents a model of intestinal infection that could be used to assess these underpinnings of catch-up growth.

Mice infected with wild-type C. rodentium had a much more severe growth response than mice infected with a mutant strain of C. rodentium. This mutant strain was deficient in 3 genes that belong to the serine protease autotransporters of Enterobacteriaceae (SPATEs)[12, 14]. These genes appear to be important for colonization and pathogenesis, potentially accounting for the decrease in virulence of this strain and the relative preservation of weight gain and linear growth, though this remains to be further characterized. Clearly, the data in these experiments are observational in nature; continued work using this model will be needed to determine the exact mechanisms of growth suppression in these settings. For example, we lacked data regarding shedding and intestinal colonization up to day 20 postinfection as well as data linking the degree of shedding and colonization to the degree of growth failure and were thus unable to determine the exact role of on-going infection and recovery on subsequent catch-up growth. Multiple other questions of pathogen-specific mechanism remain. C. rodentium is an attaching and effacing pathogen, similar to enteropathogenic E. coli (EPEC). Further experiments are required to determine whether this degree of growth failure might be associated with other pathogens, including

Campylobacter, Cryptosporidium and enteroaggerative E. coli-and whether the growth failure is directly related to the virulence of the organism. Assessment of intestinal colonization using RT-PCR would improve sensitivity and specificity of detection of the type of microorganism involved. Finally, further research regarding intestinal infectious models should also be focused on the relationship between intestinal barrier function, classical intestinal morphology, local inflammatory biomarkers and linear growth failure.

This study also had several methodological limitations. Animal length was measured in all animals using general anesthesia to provide the opportunity to have repeated measures in 
each animal over the course of treatment, (as has been described previously [19, 37]); any effect of this on the animal is not clear but would have been expected to affect all animals equally. While the measurements we used are customary, they examine the axial skeleton only. Femur length would be the best surrogate measure to examine the appendicular skeleton. We only followed animals for 20 days after infection, to an absolute age of 48-49 days. This is a time point when mice are growing at a noticeable rate. Nevertheless, the importance of catch-up growth (or the lack thereof) relates most to whether adult height is preserved. This requires longer follow-up time and may be problematic in rodents, in whom growth plates do not reach complete fusion as seen in humans. Further assessment will be needed to assess whether mice infected with $C$. rodentium reach a similar near-final length as uninfected animals.

In conclusion, we found that infection with wild type $C$. rodentium resulted in poor weight gain and linear growth failure-similar to growth patterns observed in early childhood in developing areas of the world where enteral infections are endemic. In this model, infection was associated with low levels of IGF-1, similar to food-restricted animals. Overall, growth suppression was most closely linked to elevations in systemic inflammatory cytokines. More investigations using this model are needed to further determine specific mechanisms suppressing growth during intestinal infection.

\title{
Acknowledgments
}

This research was funded by National Institutes of Health HD060739-01 (MDD), AI-033096 (JPN) and DK084045 (JLF) and the Bill and Melinda Gates Foundation OPP1137923 (MDD and JPN). The funding sources had no involvement in the preparation of the manuscript or in the collection, analysis or interpretation of the data. Authors' contributions: MDD participated in the design and analysis of the research, was responsible for the write-up and had primary responsibility for the final content. VV participated in the design and acquisition of the data and analysis of the research. MG participated in the acquisition of the data. JLF participated in the study design and acquisition of the data. RMS participated in the study design and acquisition of the data. FRP participated in the study design and analysis. JPN participated in the study design, analysis and write-up of the data. All authors provided final approval of the submitted and revised manuscript.

\author{
Abbreviation list \\ CFU colony-forming units \\ INF- $\gamma \quad$ interferon- $\gamma$ \\ IL-6 interleukin-6 \\ IL-10 interleukin-10 \\ IGF-1 insulin-like growth factor-1 \\ PBS phosphate-buffered saline \\ TNBS trinitrobenzene sulfonic acid \\ TNF- $a$ tumor necrosis factor- $a$
}




\section{References}

1. Walker CL, Rudan I, Liu L, Nair H, Theodoratou E, Bhutta ZA, O’Brien KL, Campbell H, Black RE. Global burden of childhood pneumonia and diarrhoea. Lancet. 2013; 381:1405-16. [PubMed: 23582727]

2. Black RE, Allen LH, Bhutta ZA, Caulfield LE, de Onis M, Ezzati M, Mathers C, Rivera J. Maternal and child undernutrition: global and regional exposures and health consequences. Lancet. 2008; 371:243-60. [PubMed: 18207566]

3. Jones AD, Rukobo S, Chasekwa B, Mutasa K, Ntozini R, Mbuya MN, Stoltzfus RJ, Humphrey JH, Prendergast AJ. Acute illness is associated with suppression of the growth hormone axis in Zimbabwean infants. Am J Trop Med Hyg. 2015; 92:463-70. [PubMed: 25535308]

4. Bartz S, Mody A, Hornik C, Bain J, Muehlbauer M, Kiyimba T, Kiboneka E, Stevens R, Bartlett J, St Peter JV, Newgard CB, Freemark M. Severe acute malnutrition in childhood: hormonal and metabolic status at presentation, response to treatment, and predictors of mortality. J Clin Endocrinol Metab. 2014; 99:2128-37. [PubMed: 24606092]

5. Checkley W, Buckley G, Gilman RH, Assis AM, Guerrant RL, Morris SS, Molbak K, ValentinerBranth P, Lanata CF, Black RE. Multi-country analysis of the effects of diarrhoea on childhood stunting. Int J Epidemiol. 2008; 37:816-30. [PubMed: 18567626]

6. DeBoer MD, Scharf RJ, Leite AM, Férrer A, Havt A, Pinkerton R, Lima AA, Guerrant RL. Systemic inflammation, growth factors, and linear growth in the setting of infection and malnutrition. Nutrition. 2017; 33:248-53. [PubMed: 27712965]

7. Richard SA, Black RE, Gilman RH, Guerrant RL, Kang G, Lanata CF, Mølbak K, Rasmussen ZA, Sack RB, Valentiner-Branth P, Checkley W. Network CMaI. Catch-up growth occurs after diarrhea in early childhood. J Nutr. 2014; 144:965-71. [PubMed: 24699805]

8. Boersma B, Wit JM. Catch-up growth. Endocr Rev. 1997; 18:646-61. [PubMed: 9331546]

9. de Wit CC, Sas TC, Wit JM, Cutfield WS. Patterns of catch-up growth. J Pediatr. 2013; 162:415-20. [PubMed: 23153864]

10. Collins JW, Keeney KM, Crepin VF, Rathinam VA, Fitzgerald KA, Finlay BB, Frankel G. Citrobacter rodentium: infection, inflammation and the microbiota. Nat Rev Microbiol. 2014; 12:612-23. [PubMed: 25088150]

11. Borenshtein D, Fry RC, Groff EB, Nambiar PR, Carey VJ, Fox JG, Schauer DB. Diarrhea as a cause of mortality in a mouse model of infectious colitis. Genome Biol. 2008; 9:R122. [PubMed: 18680595]

12. Vijayakumar V, Santiago A, Smith R, Smith M, Robins-Browne RM, Nataro JP, Ruiz-Perez F. Role of class 1 serine protease autotransporter in the pathogenesis of Citrobacter rodentium colitis. Infect Immun. 2014; 82:2626-36. [PubMed: 24711562]

13. Hart E, Yang J, Tauschek M, Kelly M, Wakefield MJ, Frankel G, Hartland EL, Robins-Browne RM. RegA, an AraC-like protein, is a global transcriptional regulator that controls virulence gene expression in Citrobacter rodentium. Infect Immun. 2008; 76:5247-56. [PubMed: 18765720]

14. Ruiz-Perez F, Nataro JP. Bacterial serine proteases secreted by the autotransporter pathway: classification, specificity, and role in virulence. Cell Mol Life Sci. 2014; 71:745-70. [PubMed: 23689588]

15. Sundstrom J, Sullivan L, D’Agostino RB, Levy D, Kannel WB, Vasan RS. Relations of serum uric acid to longitudinal blood pressure tracking and hypertension incidence. Hypertension. 2005; 45:28-33. [PubMed: 15569852]

16. Li L, Shi QG, Lin F, Liang YG, Sun LJ, Mu JS, Wang YG, Su HB, Xu B, Ji CC, Huang HH, Li K, Wang HF. Cytokine IL-6 is required in Citrobacter rodentium infection-induced intestinal Th17 responses and promotes IL-22 expression in inflammatory bowel disease. Mol Med Rep. 2014; 9:831-6. [PubMed: 24430732]

17. Nyagode BA, Lee CM, Morgan ET. Modulation of hepatic cytochrome P450s by Citrobacter rodentium infection in interleukin-6- and interferon-\{gamma $\}$-null mice. J Pharmacol Exp Ther. 2010; 335:480-8. [PubMed: 20719939]

18. Richardson TA, Sherman M, Antonovic L, Kardar SS, Strobel HW, Kalman D, Morgan ET. Hepatic and renal cytochrome p450 gene regulation during citrobacter rodentium infection in wild- 
type and toll-like receptor 4 mutant mice. Drug Metab Dispos. 2006; 34:354-60. [PubMed: 16339354]

19. Ballinger AB, Azooz O, El-Haj T, Poole S, Farthing MJ. Growth failure occurs through a decrease in insulin-like growth factor 1 which is independent of undernutrition in a rat model of colitis. Gut. 2000; 46:694-700. [PubMed: 10764714]

20. Ballinger AB, Camacho-Hubner C, Croft NM. Growth failure and intestinal inflammation. Qjm. 2001; 94:121-5. [PubMed: 11259686]

21. DeBoer MD, Li Y, Cohn S. Colitis causes delay in puberty in female mice out of proportion to changes in leptin and corticosterone. J Gastroenterol. 2010; 45:277-84. [PubMed: 20072791]

22. DeBoer MD, Li Y. Puberty is delayed in male mice with dextran sodium sulfate colitis out of proportion to changes in food intake, body weight, and serum levels of leptin. Pediatr Res. 2011; 69:34-9. [PubMed: 20940665]

23. DeBoer MD, Steinman J, Li Y. Partial normalization of pubertal timing in female mice with DSS colitis treated with anti-TNF-a antibody. J Gastroenterol. 2012; 47:647-54. [PubMed: 22322660]

24. DeBoer MD, Denson LA. Delays in puberty, growth, and accrual of bone mineral density in pediatric Crohn's disease: despite temporal changes in disease severity, the need for monitoring remains. J Pediatr. 2013; 163:17-22. [PubMed: 23522861]

25. Gupta N, Lustig RH, Kohn MA, McCracken M, Vittinghoff E. Sex differences in statural growth impairment in Crohn's disease: role of IGF-1. Inflamm Bowel Dis. 2011; 17:2318-25. [PubMed: 21287667]

26. De Benedetti F, Alonzi T, Moretta A, Lazzaro D, Costa P, Poli V, Martini A, Ciliberto G, Fattori E. Interleukin 6 causes growth impairment in transgenic mice through a decrease in insulin-like growth factor-I. A model for stunted growth in children with chronic inflammation. J Clin Invest. 1997; 99:643-50. [PubMed: 9045866]

27. Thissen JP, Ketelslegers JM, Underwood LE. Nutritional regulation of the insulin-like growth factors. Endocr Rev. 1994; 15:80-101. [PubMed: 8156941]

28. Scacchi M, Pincelli AI, Cavagnini F. Nutritional status in the neuroendocrine control of growth hormone secretion: the model of anorexia nervosa. Front Neuroendocrinol. 2003; 24:200-24. [PubMed: 14596812]

29. DiFedele LM, He J, Bonkowski EL, Han X, Held MA, Bohan A, Menon RK, Denson LA. Tumor necrosis factor alpha blockade restores growth hormone signaling in murine colitis. Gastroenterology. 2005; 128:1278-91. [PubMed: 15887111]

30. Fan J, Li YH, Bagby GJ, Lang CH. Modulation of inflammation-induced changes in insulin-like growth factor (IGF)-I and IGF binding protein-1 by anti-TNF antibody. Shock. 1995; 4:21-6. [PubMed: 7552773]

31. Denson LA, Held MA, Menon RK, Frank SJ, Parlow AF, Arnold DL. Interleukin-6 inhibits hepatic growth hormone signaling via upregulation of Cis and Socs-3. Am J Physiol Gastrointest Liver Physiol. 2003; 284:G646-54. [PubMed: 12519742]

32. Denson LA, Menon RK, Shaufl A, Bajwa HS, Williams CR, Karpen SJ. TNF-alpha downregulates murine hepatic growth hormone receptor expression by inhibiting Sp1 and Sp3 binding. The Journal of Clinical Investigation. 2001; 107:1451-8. [PubMed: 11390427]

33. Jain S, Golde DW, Bailey R, Geffner ME. Insulin-like growth factor-I resistance. Endocr Rev. 1998; 19:625-46. [PubMed: 9793761]

34. Wong SC, Dobie R, Altowati MA, Werther GA, Farquharson C, Ahmed SF. Growth and the Growth Hormone-Insulin Like Growth Factor 1 Axis in Children With Chronic Inflammation: Current Evidence, Gaps in Knowledge, and Future Directions. Endocr Rev. 2016; 37:62-110. [PubMed: 26720129]

35. MacRae VE, Farquharson C, Ahmed SF. The restricted potential for recovery of growth plate chondrogenesis and longitudinal bone growth following exposure to pro-inflammatory cytokines. $\mathrm{J}$ Endocrinol. 2006; 189:319-28. [PubMed: 16648299]

36. Baron J, Klein KO, Yanovski JA, Novosad JA, Bacher JD, Bolander ME, Cutler GB. Induction of growth plate cartilage ossification by basic fibroblast growth factor. Endocrinology. 1994; 135:2790-3. [PubMed: 7988472] 
37. Sundström K, Cedervall T, Ohlsson C, Camacho-Hübner C, Sävendahl L. Combined treatment with GH and IGF-I: additive effect on cortical bone mass but not on linear bone growth in female rats. Endocrinology. 2014; 155:4798-807. [PubMed: 25243853] 
A

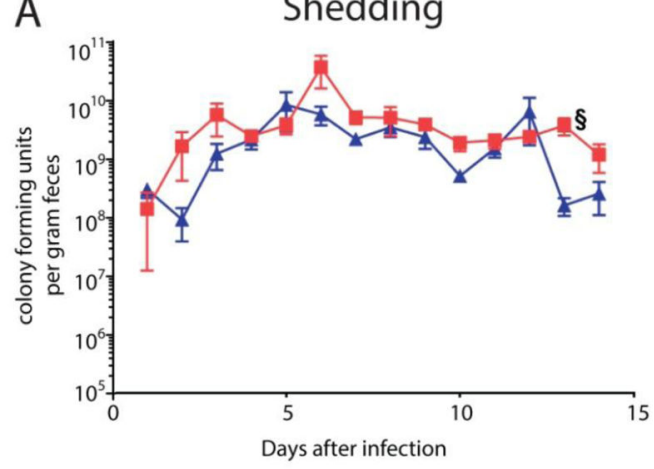

B

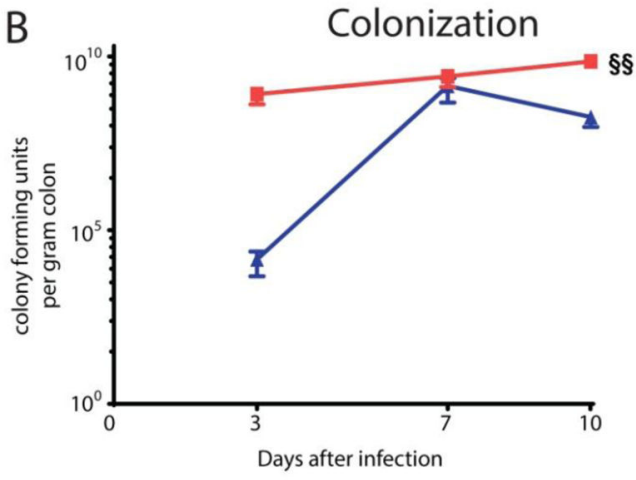

- Wild-type $C$. rodentium

$\triangle$ Mutant C. rodentium

Figure 1. $C$. rodentium bacterial shedding and colonization following infection Values are means (+/- SEM) colony forming units (CFU) of $C$. rodentium bacteria per gram of stool (A, shedding data) or per gram of colon (B, colonization data) following inoculation with wild type $C$. rodentium or mutant $C$. rodentium. $\S \mathrm{p}<0.05$ vs. mutant $C$. rodentium; $\S \S$ p $<0.001$ vs. mutant $C$. rodentium 

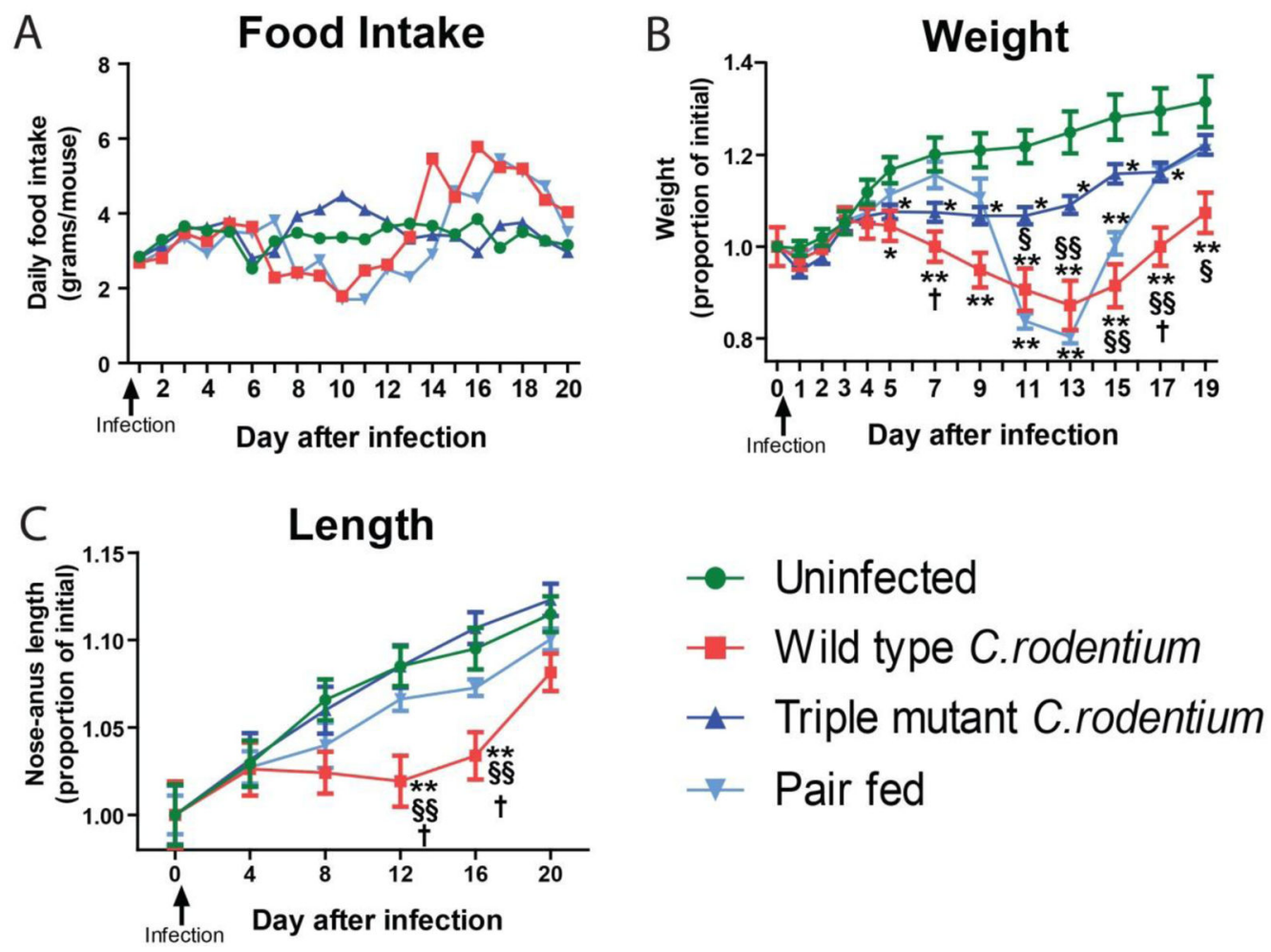

Figure 2. Food intake, weight gain and linear growth measures over the course of experiment Values are means (+/-SEM) by treatment group for animals infected with wild type Citrobacter rodentium, mutant $C$. rodentium, uninfected, and pair-fed groups: A. daily food intake. B. weight; C. length, nose-to-anus. Significance between groups: * $\mathrm{p}<0.05$ vs. uninfected; $* * \mathrm{p}<0.01$ vs. uninfected; $\S \mathrm{p}<0.05$ vs. mutant $C$. rodentium; $\S \S \mathrm{p}<0.01$ vs. mutant $C$. rodentium $\dagger \mathrm{p}<0.05$ vs. pair-fed. 

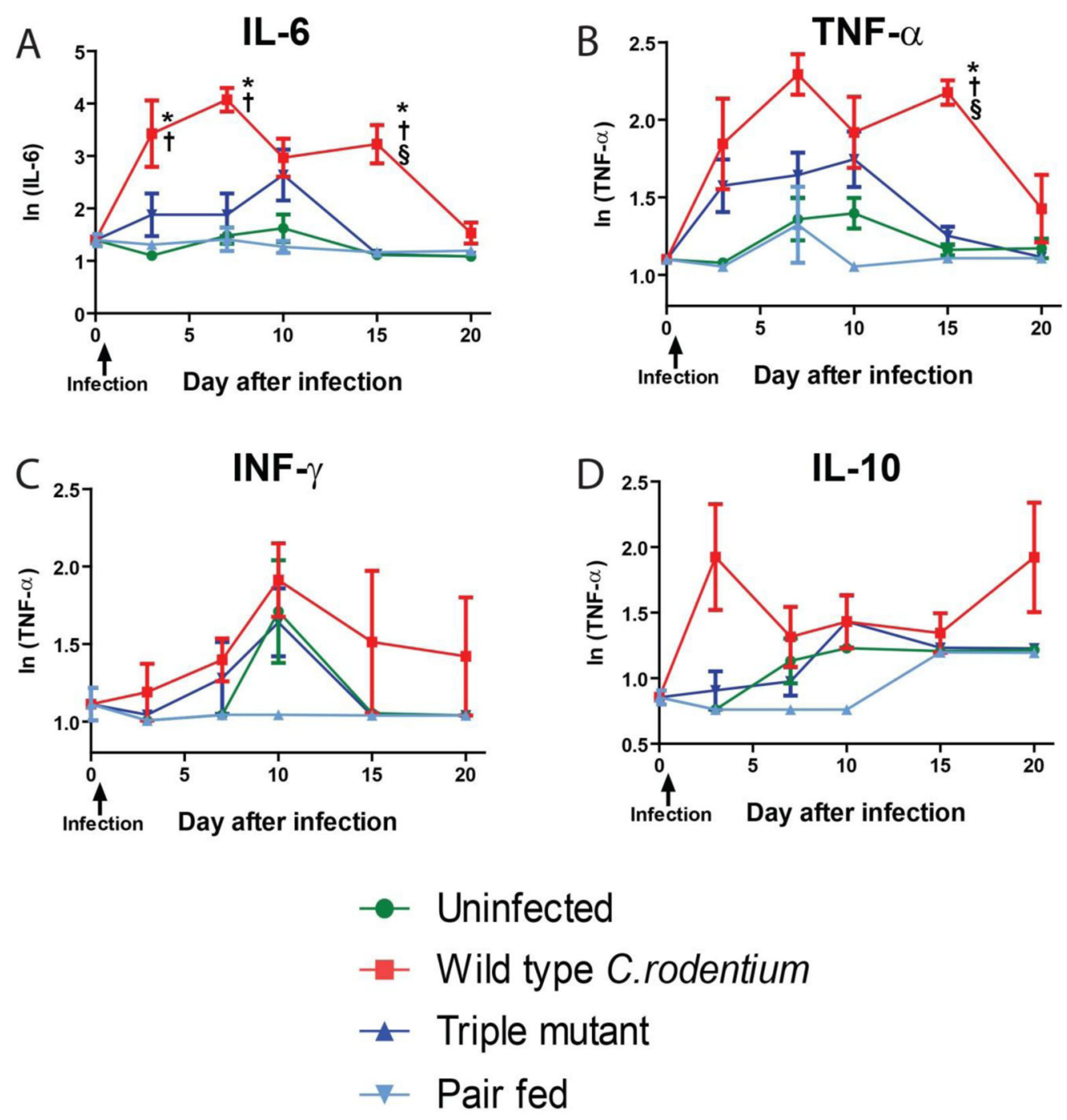

Figure 3. Serum cytokine levels over the course of experiment

Values are means (+/-SEM) by treatment group for animals infected with wild type Citrobacter rodentium, mutant $C$. rodentium, uninfected, and pair-fed groups (see text for details): A. IL-6; B. TNF-a; C. IL-10; D. interferon $\gamma$. All units are in pg/mL. Significance between groups: * $\mathrm{p}<0.001$ vs. uninfected; $\S \mathrm{p}<0.001$ vs. mutant $C$. rodentium; $\dagger \mathrm{p}<0.001$ vs. pair-fed. 


\section{IGF-1}

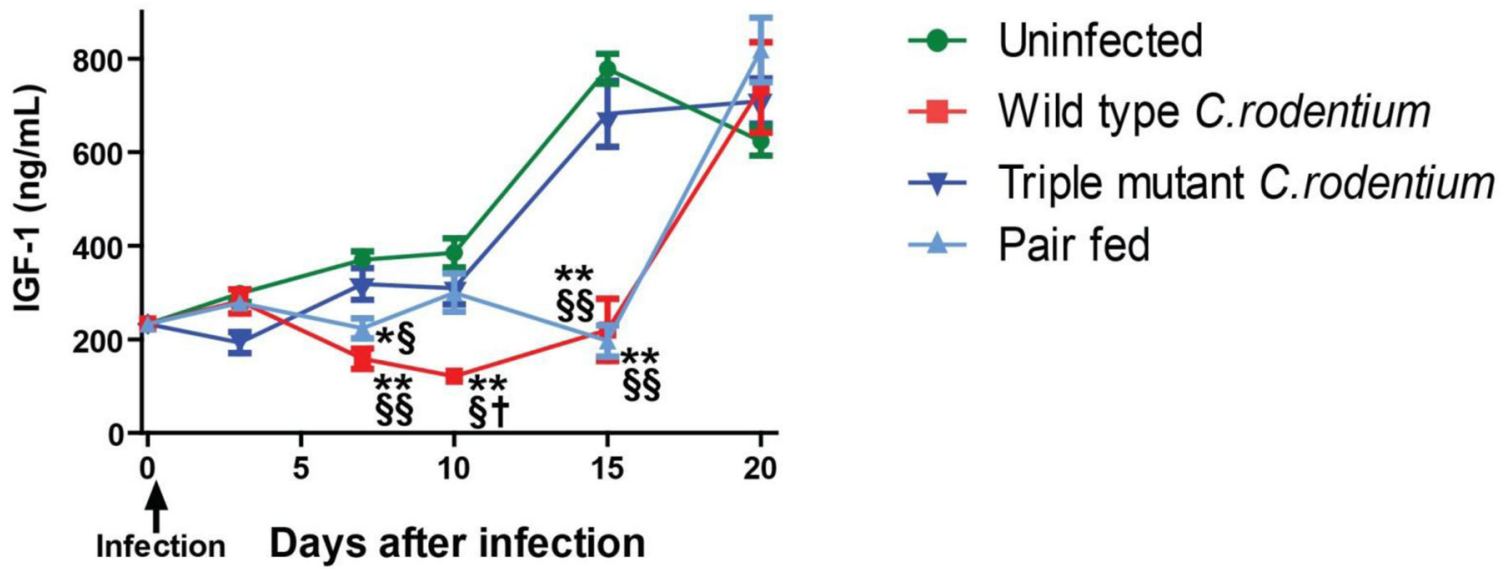

Figure 4. Serum IGF-1 levels over the course of experiment

Means (+/- SEM) of IGF-1 by treatment group for animals infected with wild type

Citrobacter rodentium, mutant $C$. rodentium, uninfected, and pair-fed groups. Statistical significance between groups: $* \mathrm{p}<0.01$ vs. uninfected; $* * \mathrm{p}<0.001$ vs. uninfected; $\S \mathrm{p}<0.05$ vs. mutant $C$. rodentium; $\S \S \mathrm{p}<0.001$ vs. mutant $C$. rodentium; $\dagger \mathrm{p}<0.01$ vs. pair-fed. 

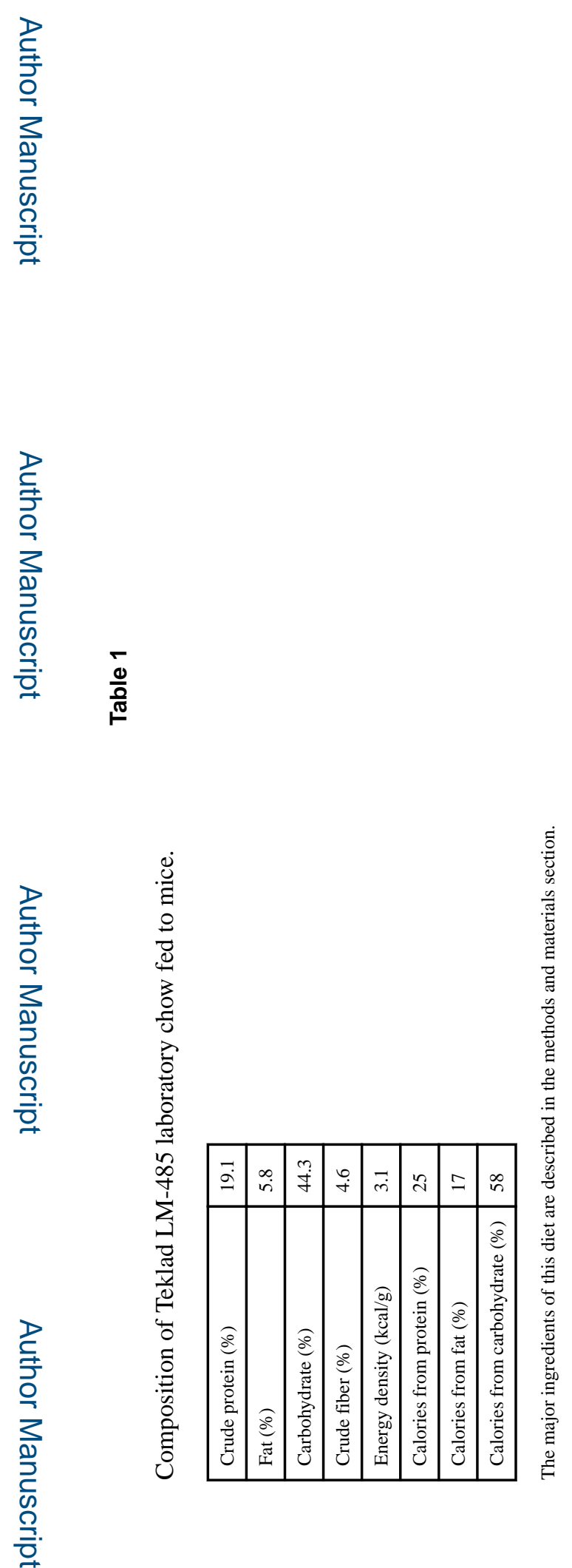

Nutr Res. Author manuscript; available in PMC 2018 March 01. 


\section{롤 \\ ํㅗㄹ}

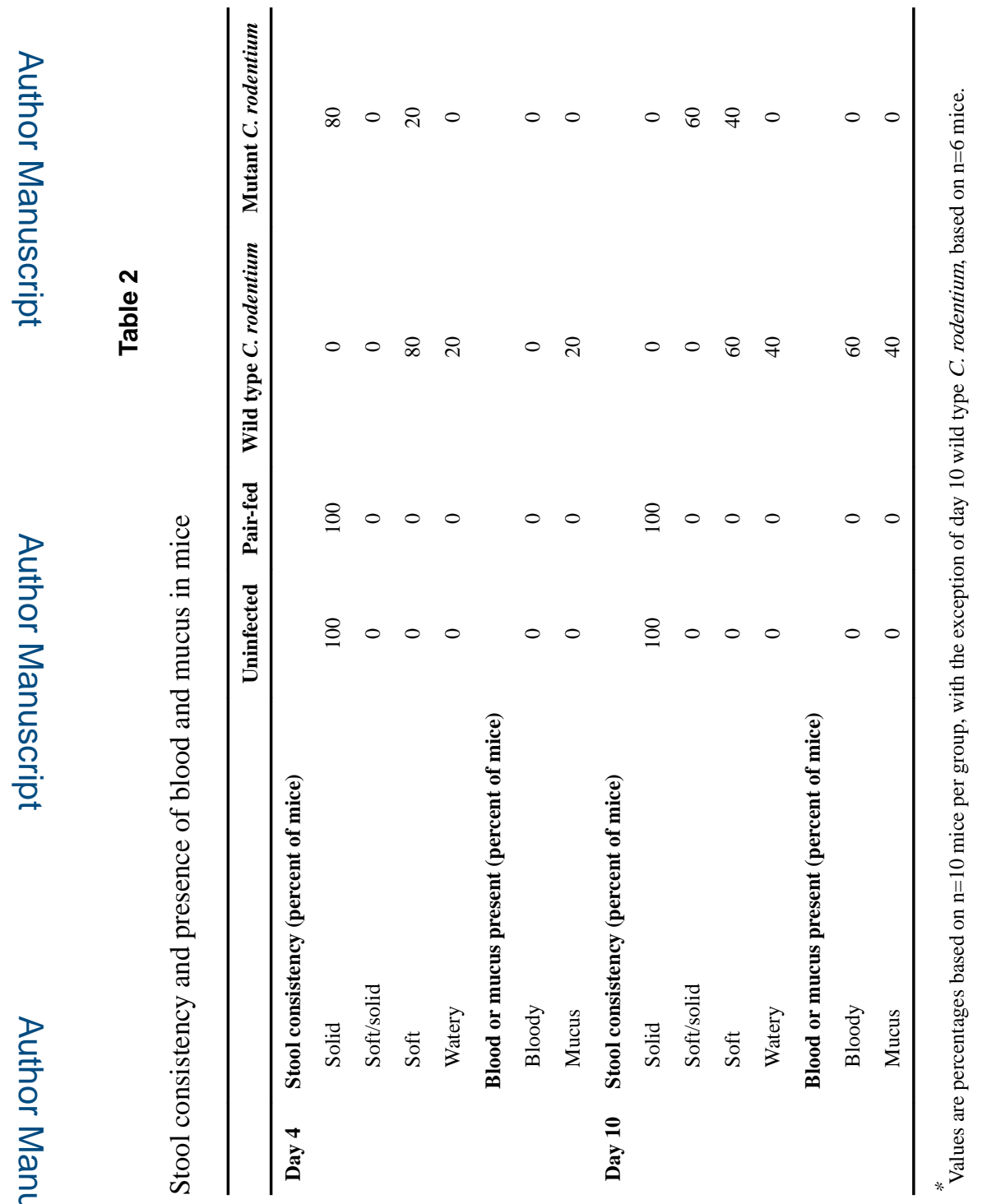

Nutr Res. Author manuscript; available in PMC 2018 March 01. 